\title{
Solution-Focused Brief Therapy
}

\author{
F. P. Bannink
}

Published online: 22 February 2007

(C) Springer Science+Business Media, LLC 2007

\begin{abstract}
A brief history on Solution-Focused Brief Therapy is given, followed by pragmatic assumptions, offering a new 'lens' for looking at clients. SFBT originated from social constructionism: reality is subjective and there are many realities, all equally correct. Outcome studies indicate that SFBT has a positive effect in less time and satisfies the client's need for autonomy. Indications and differences between problem-focused psychotherapy and SFBT are outlined. SFBT can be seen as a form of cognitive behavior therapy. Instead of reducing problems, the solution-focused question is: 'What would you rather have instead?' A lot could change for the better for both clients and therapists.
\end{abstract}

Keywords Solution-Focused Brief Therapy

\section{Introduction}

Suppose you are hungry and decide to eat in a restaurant. After having waited for some time, you are invited to take a seat and the manager introduces himself. He asks you questions regarding your hunger: 'How hungry are you? For how long have you been preoccupied with this feeling? Were you hungry in the past? What role did hunger play at home with your family or with other relatives? What disadvantages and possibly advantages does hunger have for you?' After this, having become even hungrier, you ask if you can now eat. But in addition the manager wants you to complete some questionnaires about hunger (and perhaps about other

F. P. Bannink $(\bowtie)$

Clinical Psychologist,

Schubertstraat 17, 1077 GP Amsterdam,

The Netherlands

e-mail: fpbannink@planet.nl,www.fpbannink.com issues that the manager finds important). Once everything is finished, a meal is served to you that you did not order, but that the manager claims is good for you and has helped other hungry people. What are the chances of you leaving the restaurant feeling satisfied?

Within psychotherapy there is an evolution from lengthy to short forms of treatment and from cure to prevention. There is a process of patients becoming clients and of using facilitators rather than traditional practitioners. The focus shifts from mental illness to mental health. Seligman, the founding father of positive psychology, introduced the term learned optimism (Seligman, 2002). Positive psychology emphasizes the client's strengths and the supposition that happiness is not the result of having the right genes or mere chance, but is to be found through identifying and using the strong points that the client already possesses, such as friendliness, originality, humor, optimism and generosity.

Clients become increasingly emancipated. The therapist adopts an enabling role, coaching the client in exploring his own way of solving the problems experienced, thereby using his own competence to the greatest extent possible. SolutionFocused Brief Therapy (SFBT) supports this evolution and abandons the 'medical model,' in which the therapist's role can be likened to that of the aforementioned restaurant manager.

Throughout the text 'he' is interchangeable with 'she'

\section{A brief history of SFBT}

SFBT was developed during the 1980 s by de Shazer and Berg. They expanded upon the findings of Watzlawick, Weakland and Fisch (1974), who believed that the attempted solution would often perpetuate the problem, rather than solving it and that an understanding of the origins of the 
problem is not (always) necessary. SFBT proposes: the development of a solution is not necessarily related to the problem; the client is the expert; if it is not broken, do not fix it; if something works, continue with it; if something does not work, do something else (de Shazer, 1985).

de Shazer and Berg found that three specific types of therapist behavior would result in clients being four times more likely to speak about solutions, change and resources: eliciting questions such as 'What would you like instead of the problem? What is better?,' questions about details such as 'How did you do that exactly? What exactly did you do differently?' and verbal rewards: giving compliments and asking competence questions such as 'How did you manage to do that? Where did you get that good idea?'

Psychiatrist Milton Erickson also contributed to the development of SFBT: he asked students to read the final page of a book and then to speculate on what had preceded. In the same vein SFBT begins from the perceived goal of the client. Erickson also emphasized the competence of the client and considered it necessary to search for possibilities for action (and change) revealed by the client, rather than adapting the therapy to a diagnostic classification (Rossi, 1980).

\section{Assumptions with an eye on solutions}

Selekman (1993) gives a number of pragmatic solutionfocused assumptions. They offer therapists a new 'lens' for looking at their clients. The term resistance suggests that the client is not willing to change and that the therapist is detached from the treatment system (de Shazer, 1984). Therefore resistance is not a useful concept. It is preferable to approach each client in a cooperative manner rather than from a position of resistance, power and control. The therapist uses the client's strong points and resources, his words and opinions, and asks competence questions. Change is a continuous process, stability is an illusion. The question is not whether but when change will occur. The client can be helped in making positive self-fulfilling prophecies. A direct relation appears to exist between talking about change and the actual result. It is helpful to talk about successes in the past, present and future. Collecting information about past and present failures, however, often leads to negative outcomes.

As soon as the client is invited to notice and value small changes (the exceptions), he will begin to expect other changes to take place and will start believing in the snowball effect. Often the beginnings of a solution already lie in the client but remain unnoticed. These are the exceptions to the problem (hidden successes). Inquiring into the exceptions gives insight into which positive actions could happen to a larger extent or more often; inquiring into hypothetical solutions also gives insight into the direction of the search.
Because the client is the expert and finds the solutions himself, they suit him and are compatible with his situation, are found quickly and will endure. Solution-focused therapists maintain a non-pathological view on people. Generally people have or have had one or more difficulties in their life. These may have become chronic, depending on the way in which the client or those around him (including therapists) react. The client possesses resources and competences that can be drawn on. As a result, hope and self-confidence can be rebuilt. Walter and Peller (2000) give three solution-focused questions which invite their clients to relate their 'success stories': How did you do that?, How did you decide to do that?, How did you manage to do that? The first question departs from the assumption that the client has done something and therefore supposes action, competence and responsibility. The second question departs from the assumption that the client has taken an active decision, affording him the opportunity to write a new life story, with influence on his own future. The third question invites the client to relate his successes. Watzlawick et al. (1974) state that problems are unsuccessful attempts to resolve difficulties. They name three ways in which the client may unsuccessfully deal with his problems: action is necessary, but client does nothing (denial of the problem); action is undertaken, but this is not necessary or necessary to a lesser extent (client follows a diet that is so strict he cannot possibly maintain it); action is undertaken on the wrong logical level. For instance: a client requests someone else to behave 'spontaneously.' This is impossible because on complying with the request it is no longer a spontaneous action. The basic assumption in SFBT is that no problem is always there to the same extent and that in order to solve it, not a great deal about the problem needs to be known. The therapist may investigate what the client is doing differently when the problem is not there or there to a lesser extent, or what is different about those times when there ceases to be a problem for a while. The client defines the goal for treatment. It is important to receive from the client a 'videotape description' of what his life will look like once his goal is reached. Aristotle cites the archer as his favorite example in describing moral wisdom. An archer comprehends his task if firstly he knows what his target is and secondly if he is aware of all circumstances (the means) that determine the situation in which he has to shoot. He has assessed the strength and direction of the wind, the characteristics of the arrow and the tension of the bow. Aristotle sees the wise person as such an archer, someone with knowledge of the goal (the target) and of the means to reach the goal. Much solution-focused literature mentions treatment goals (plural). In my opinion, however, it is preferable to speak of a treatment goal (singular), since there is only one goal that the client wants to reach. There are many means imaginable that may bring the client closer to the desired goal. Experience shows that if the client is questioned with respect 
to goals (plural), the chances are high that he will mention means rather than the goal itself. Should a means appear impossible, then the therapy is likely to stagnate if the focus fails to stay with the goal. Einstein believed that our theories determine what we observe. Reality is observer-defined and the therapist participates in co creating the therapy system's reality. A psychoanalytical therapist will probably see unsolved conflicts and psychological 'deficits.' It is impossible for psychotherapists to not have a theory. Solution-focused therapists are co-authors who help the client rewrite his problem saturated story. de Shazer (1984) sees therapist and client as tennis players on the same side of the net, the therapist is not an observer on the sidelines. There exist no definitive explanations or descriptions of reality. There are many ways to look at a situation, all equally 'correct.' Solution-focused therapists should not be too attached to their own preference models: nothing is more dangerous than an idea, if that is the only one you have.

\section{Theoretical background}

SFBT originated from social constructionism (Cantwell \& Holmes, 1994), which claims that the individual's idea about what is real-including the idea of the nature of his problems, competences and possible solutions-is being construed in daily life in communication with others. In other words: people confer meaning to things in communication with others; in this language plays a central role. Shifts in the perceptions and definitions of the client take place within contexts, in society. Individuals always live in ethnic, family, national, socio-economic and religious contexts. They adapt their meaning conferment under the influence of the society in which they live. As early as the third century B.C. the ancient Greeks were aware of the distinction between observing and defining reality. Following one path were the Stoics: they learned to follow only reason, to banish one's passions and to ignore pain. To reach an imperturbable state when encountering pain, harm or difficulties was considered the ultimate achievement: how not to be unhappy. One could attain this through not heeding emotions. Following a different path were the Epicurists, who believed that being civilized and leading a virtuous life were the ultimate goals of mankind: how to be happy. This could be achieved through having positive emotions. From the socialconstructionist perspective consideration is given to how the therapist can contribute to the creation of a new reality for the client. The capacity of the client for change is connected to his ability to begin seeing things differently. These shifts in observation and definitions of reality occur particularly in the solution-focused conversation on the desired future and usable exceptions. The solution-focused questions are intended to define the goal and the solutions, which (for the most part) are assumed to be already present in the client's life. The questions 'that make a difference' relate to the manner in which the client is managing despite his problems, to what he feels is already going well and should persist, and to what has improved since making the appointment. Questions regarding goal formulation, exceptions, scaling and competences extract the relevant information. Here a 'different layer' of the client is tapped, which usually remains unexplored in problem-focused therapy. The therapist is not the expert with all the answers, but allows himself to be informed by the client who creates his own solutions. The therapist is expert though in asking the right solution-focused questions (Bannink, 2006c) and in motivating behavioral change by relating to the motivation of the client. In addition he uses his expertise in structuring the conversation and in applying operant reinforcement principles.

I have two suppositions that require further research. The first is that the effect of SFBT may be explained through the Bio-Information Theory of Lang (1985). According to Lang's theory a change in the emotional reaction to certain events and situations implies changing the associative networks that lie at the basis of those emotional reactions. The knowledge coded in the memory needs to be altered. Since the response codes are the prime determining elements in those networks, the biggest gains can be made through influencing precisely those responses. In concrete terms this implies that a change in behavior appears the best way to modify emotional knowledge. However, since knowledge cannot be erased just like that, new knowledge needs to be added; some additional learning is required. That is why contraconditioning is applied; the client learns to connect other behavioral tendencies to the experienced stimulus constellations by homework suggestions like 'pretend you have already reached your goal' or 'do something different.'

My second supposition concerns recent insights in the field of neurobiology and knowledge about the functioning of both cerebral hemispheres (Siegel, 1999). The right hemisphere deals principally with processing non-verbal aspects of communication, such as seeing images and feeling primary emotions. The right hemisphere is involved in the understanding of metaphors, paradoxes and humor. Reading fiction and poetry activates the right hemisphere whereas the reading of scientific texts essentially activates the left hemisphere. There the processes relating to the verbal meaning of words, also called 'digital representations,' take place. The left hemisphere is occupied with logical analyses (causeeffect relations). Linear processes occurring are reading the words in this sentence, aspects of attention and discovering order in the events of a story. Our language based communication is thus dominated by the left hemisphere. Some authors are of the opinion that the right hemisphere sees the world more as it is and has a better overview of the context, 
whereas the left hemisphere tends to departmentalize the information received. The left hemisphere sees the trees, the right hemisphere the forest. Try listening to a favorite piece of music through headphones, first with your left ear, then with your right; what differences do you experience? Several studies have shown that most (right-handed) people prefer to listen to music with their left ear (connected to the right hemisphere), rather than with their right ear (connected to the left hemisphere). If one listens to music with the left ear, this gives a more holistic sensation, a 'floating with the flow of the music,' whereas the experience is different if one listens with the right ear. This tendency is reversed in professional musicians. An explanation for this is that they listen to music in a more analytical way than 'the casual listener.' Working in a solution-focused manner, with a high utilization of imagination, such as 'mental rehearsal' and hypothetical questions, stimulates the nonverbal and holistic capacities of the right hemisphere. The success of solution-focused therapy might be (partly) explained in the way it addresses both hemispheres of the brain.

\section{Empirical evidence}

In SFBT there are a growing number of outcome studies. When determining the effectiveness of a therapy it is important to not only register progress on arbitrary metrics, but also to monitor improvement on points that the client himself finds relevant (Kazdin, 2006). He argues for the addition of clinical relevance: the client himself should determine whether in his daily life he has found the treatment useful.

de Shazer (1991), de Jong and Berg (1997), Miller, Hubble, and Duncan (1996) all carried out studies regarding the success of SFBT. However these studies are not controlled studies (they are one group pre-post studies) and hence cannot be considered satisfactory evidence.

Gingerich and Eisengart (2000) gave an overview of 15 outcome studies of SFBT, in which they distinguished between statistically well monitored and less well monitored research. One of the statistically well monitored analyses demonstrated that SFBT yields results comparable to those of interpersonal psychotherapy with depressed students. These outcome studies are generally small sample studies, conducted by investigators with allegiance to SFBT.

Stams, Dekovic, Buist, and de Vries (2006) conducted a meta-analysis of 21 international studies including 1421 clients to achieve quantitative evidence for the efficacy of SFBT. They found that although SFBT does not have a larger effect than problem-focused therapy, it does have a positive effect in less time and satisfies the client's need for autonomy more than do traditional forms of psychotherapy.

\section{Indications and contraindications of SFBT}

Much literature exists regarding SFBT (de Jong \& Berg, 1997; de Shazer, 1984, 1985, 1991, 1994; Walter \& Peller, 1992, 2000; Duncan, Miller, \& Sparks, 2004; Duncan, 2005; Bannink, 2005, 2006a,b,c,d). SFBT is applied to adults with diverse problems, varying from alcohol abuse (Berg \& Miller, 1992), posttraumatic stress disorders (Dolan, 1991; O'Hanlon \& Bertolino, 1998), personality disorders and psychoses (O'Hanlon \& Rowan, 1999). SFBT is applied to children and adolescents (Selekman, 1993, 1997; Berg \& Steiner, 2003), to groups (Metcalf, 1998), in education (Goei \& Bannink, 2005), in working with mentally handicapped clients (Westra \& Bannink, 2006), in management \& coaching (Cauffman, 2003) and in mediation (Bannink, 2006a,b).

SFBT is suitable for a wide variety of clients, whereby it is of importance that the client has a goal (or is able to formulate one during psychotherapy). Although the number is not fixed in advance, an average of three conversations appears to be sufficient. A contraindication is the situation where it is impossible to establish a dialogue with the client (medication might be indicated in the case of acute psychosis or deep depression). At a later stage medication often helps a client undertake solution-focused conversations. If a client has a mental handicap good progress can be made with SFBT, sometimes together with solution-focused help of those caring for the client (Westra \& Bannink, 2006). Another contraindication concerns a well executed SFBT which has yielded disappointing results. In these situations diagnostic research or a lengthier form of psychotherapy might be indicated. However, if the therapist is not prepared or not able to let go of his attitude as an expert, solution-focused therapy will not work. The final contraindication relates to some institutions maintaining waiting lists for reasons of financial security. SFBT is brief, so waiting lists can be reduced relatively quickly.

\section{Differences between problem-focused psychotherapy and SFBT}

Many differences exist between SFBT and problem-focused types of psychotherapy which focus on in-depth exploration of the life history of the client and his family, problem description and data collection in a problem analysis, diagnosis made by the therapist, formulation of goals, treatment plan and interventions by the therapist, execution of interventions by the client and evaluation of the treatment. The attitude of the therapist is 'leading': he is the expert who advises the client.

In SFBT the therapist's opening question following the preliminary introductions, establishing rapport and an 
explanation of the structure of the session is: 'What brings you here?' or 'What needs to come out of this session/these sessions?' The client may react to this with a description of his problem, to which the therapist listens respectfully, or he may indicate the goal of the session/sessions. A clearly formulated goal is developed. Here the client cooperates in envisaging and describing what will be different in his life once the problem is solved. Sometimes the 'miracle question' is put forward: 'Imagine a miracle occurring tonight that would (sufficiently) solve the problem which brought you here, but you were unaware of this as you were asleep: how in the morning would you notice that this miracle had taken place? What would be different? What would you be doing differently? What else? Who would be the next person to notice that the miracle has happened? How would this person notice? How would he react?' Many more questions can be asked to invite the client to describe the day after the miracle has occurred in as elaborate and concrete a manner as possible. It is important to encourage the patient to describe the miracle in terms of the presence of desired behavior rather than the absence of undesired behavior. Thus when the client says that he then will no longer be depressed, the therapist will ask: 'What would you like to be instead?' The therapist may then ask what the first thing will be that he would take up to make (part of) the miracle happen. In order to establish the client's goal, the therapist may also ask how the client would notice that he will not need to return. What would be different?' The client's motivation is assessed in the first conversation: is the relationship with the client a visitor-, a complainant- or a customer-relationship? In a visitor-relationship the client has been sent or referred by others. He does not come forward in search of help and is not suffering emotionally. The therapist may ask what the client thinks the person referring would like to see changed in his behavior and to what extent he is prepared to cooperate. In a complainant-relationship the client does have a problem and is suffering emotionally, but he does not (yet) see himself as part of the problem and/or the solution. The other person or the world needs to change, rather than himself. The therapist acknowledges the client's suffering and gives suggestions for observing the moments when the problem is no longer present or there to a lesser extent, or the moments when part of the miracle is already taking place. This client is not (yet) ready to carry out a behavior assignment, in which he should do something differently, but he may undertake an observation assignment, which does not yet involve a change in behavior. This can be interpreted as a paradoxical intervention. In a customer-relationship the client does see himself as part of the problem and/or solution and is motivated to change his behavior. This client may be given a corresponding behavior assignment ('continue with what works,' 'do something different,' 'act as if the miracle has happened') Also exceptions are explored. The therapist asks questions regarding the moments in the client's life when the problem does not occur or is less serious and who did or does what to make these exceptions happen. This replaces the invention of modification procedures undertaken by the therapist in problem-focused (behavior) therapy, because the competences already present in the client are addressed. The therapist may ask questions regarding the moments when (part of) the miracle is already occurring and how the client manages to facilitate these moments taking place. The client may be asked to repeat the exceptions, if they are deliberate. Should the exceptions occur 'spontaneously,' the client may be asked to observe what has changed during those moments and what he is then doing differently. In order to discover improvements between the application and the first meeting, which can be built upon; to measure progress in the therapy, and to measure and stimulate motivation and confidence that the problem can be solved scaling questions are used.

At the end of every session feedback is given. After a short break during which the therapist reflects on the conversation, the therapist formulates feedback for the client containing compliments and usually some suggestions. The compliments emphasize what the client is already doing in order to solve his problems. The suggestions indicate areas requiring attention by the client or possible further actions to solve the problems. The feedback focuses on what the client can start developing or changing in order to increase the chances of success with respect to reaching his goal. Every SFBT session includes an evaluation of how close the client is to achieving his goal. This is achieved through asking scaling questions, with the progress being evaluated on a scale of 10 to 0 . The conversation then focuses on this score in order to explore what is yet to be done before the client would consider the goal (sufficiently) reached and would deem himself ready to conclude the therapy. The attitude of the therapist is one of 'leading from one step behind' and 'not-knowing.'

\section{SFBT is a form of cognitive behavior therapy}

Recently attempts are made to fit SFBT into already existing models of psychotherapy. Cepeda and Davenport (2006) propose an integration of person-centered therapy, with its focus on the here and now of client awareness of self, and SFBT, with its future-oriented techniques that also raise awareness of client potentials. Although the two theories hold different assumptions regarding the therapist's role in facilitating client change, it is suggested that solution-focused techniques are often compatible for use within a person-centered approach.

From my point of view SFBT is seen as a form of cognitive behavior therapy (Bannink, 2005, 2006d). The same learning principles of classical and operant conditioning are 
applied both in regular problem-focused behavior therapy and in SFBT. Also the same behavioral therapeutic process is followed in both therapies: in SFBT behavioral analyses are made, not of the problem behavior, but of the exceptions. SFBT makes use of the principles of operant conditioning: the discussion and implementation of desired behavior is strengthened by the therapist (positive reinforcement), the discussion and implementation of undesired behavior is extinguished (frustrative non-reward) due to the minimum possible attention paid to this by the therapist. This contrasts with paying attention to, thus positively reinforcing, the same or even increased problem behavior. SFBT also makes use of the principles of classical conditioning: as a homework assignment the client may be invited to 'do something different' or to 'pretend the miracle has happened' (counter conditioning), as is applied in other forms of cognitive behavior therapy (Beck, 1995).

Problem-focused behavior therapy concentrates on decreasing problem behavior, whereas solution-focused behavior therapy concentrates on increasing behavior desired by the client. Another difference is found in the role of the therapist: in problem-focused behavior therapy the therapist is the expert who hands out the modification procedures. In SFBT the client is the expert in changing the viewing (cognitions) and doing of the problem: he has made changes before (exceptions). The attitude of the therapist is one of 'leading from one step behind' and 'not-knowing.' de Shazer (1985): 'In some sense, the therapy really adds nothing. The therapist doest not tell the clients what to do differently and does not teach the clients any new techniques. These interventions are minimally intrusive and yet their impact seems inordinately large' (p. 136).

\section{Case study}

Client is a secondary school teacher aged 50 . He has been referred by his family doctor with symptoms such as waking up early, palpitations, panic attacks, crying fits (also in the classroom) and a high blood pressure. He has been on sick-leave for eight weeks and the mere thought of returning to school provokes physical reactions, such as feeling nauseous. Since being at home the situation has deteriorated: the crying fits have become more regular and the physical symptoms have worsened. He does not use medication during the therapy. With respect to the cause of the complaints client mentions the suicide of a colleague in the previous year. He has felt alone in dealing with it and is angry about that. Further strains were placed upon him: his sick father lives at home with him and requires a lot of care. Client also relates that another colleague is experiencing psychological problems and often misses lessons due to illness, as a result of which additional hours were added to his schedule.
He is concerned that this colleague may commit suicide as well. The atmosphere between colleagues has deteriorated. Goal formulation: 'What at the end of the therapy should be achieved in order to say that the therapy has been useful?' He would like to be teaching again and get along well with his colleagues. He would like to make jokes with the pupils and feel relaxed during lessons. The therapeutic relationship is considered to be a customer-relationship: client is motivated to change his behavior. The therapist gives compliments for having looked for help and the clear manner in which he formulates his goal. The client is asked whether he would like to return and if so when.

During the second conversation, two weeks later, the therapist asks a scaling question relating to how he feels at the present time $(10=$ feeling completely well again and his goal has been achieved; $0=$ the moment when he felt worst). Client answers that he scores a 4 , whereas during the first meeting he scored a 1 . He feels more cheerful, is more active and has attended a concert; he sleeps better and feels more comfortable when he is among people. There are less panic attacks. The therapist asks him which mark he thinks his wife would give him. He thinks she would also give him a 4. The question as to how he has managed to reach a 4 so quickly from a 1 , is answered by stating that the first meeting has helped him focus his attention on where he wants to end up; in helping to achieve this he has begun to undertake some activities. He does not yet want to think about school and avoids all contact. After having complimented him on his rapid progress and the positive things he has done to achieve this, the next question is: 'What would a 5 look like?' He would then have some contact with colleagues (he indicates that he is not yet ready for this) and that his physical complaints would further diminish. As a suggestion for homework he is asked to think about what else would help achieve a 5 and to ask others close to him how they would envisage his behavior at 5 . He is also asked to observe what moments already give a flavour of a 5 and what he is doing differently at those moments. or what has changed.

In the third conversation after three weeks the opening question is 'What is better?' The physical symptoms have diminished and he has sent one of his colleagues an email with apologies for an angry reaction. He received a positive response. He told the headmaster that he would like to be scheduled again, initially for half of his usual number of lessons. The scaling question as to how confident he feels that his goal will be reached, he answers a 7-8, because he feels better rested and is happy with the friendly reactions. He has also decided to distance himself from the colleague with problems. After compliments for all that he has achieved, the conversation is concluded.

On the client's request a follow-up session takes place after three months. The answer to the question 'What is better?' is that he has returned to school and enjoys being 
back. Colleagues and pupils have received him heartily. The physical symptoms have largely disappeared; he feels active again and is not preoccupied anymore with his colleague's suicide. He has even taken up jogging. To the scaling question concerning progress he now gives himself a 9. When asked which mark he thinks his wife would give him he answers an 8 . He thinks that the head master and the school pupils would also give him an 8 , because everyone can see that he is more cheerful, is able to laugh again and make jokes. The therapist asks what he would have to do in order to revert to a 4 or even a 1 (relapse prevention). He would have to quarrel with his colleagues again, put in a lot of overtime and place great demands on himself and on the pupils. While reclining in his chair and in a jovial manner he says that he will not let it get that far again. After compliments and congratulations by the therapist for the manner in which he has managed to get his life back on track, therapy is finished. The therapist asks how he is going to celebrate this happy fact. He decides he will celebrate the positive result by taking his wife out to a candle-lit dinner.

\section{Conclusion}

Brief interventions are en vogue. Both psychotherapy and waiting lists should and can be shorter. No longer the 'moaning and complaining' attitudes of clients should be reinforced, they should be strengthened and stimulated to undertake positive action. SFBT is applied in frontline mental health care. In this way many clients can be (sufficiently) treated, without there being an extensive diagnosis. Also in chronic psychiatry SFBT is increasingly applied (O'Hanlon \& Rowan, 1999).

Psychotherapy should no longer be considered as a group of methods that makes use of psychologically validated knowledge to reduce emotional problems. The time is ripe for a positive objective. Instead of reducing problems it is possible to ask the solution-focused question: 'What would you rather have instead?' The positively formulated answer of most clients will be: happiness in a satisfying and productive life. Each client will be able to outline his or her own definition of happiness with a description of behaviors, cognitions and emotions. With the help of the therapist clients will be able to explore ways that will bring them within reach of their goal. The client is motivated to work hard, as a result of which the therapist has energy to spare at the end of the day. Conversations with clients become positive, shorter and more effective, thus SFBT is also cost-efficient. The implications of SFBT are that training in diagnostic and treatment methods of psychopathology can become shorter and be replaced by a training in SFBT. In this scenario a lot could change for the better in mental health care, for both clients and therapists.

\section{References}

Bannink, F. P. (2005). De kracht van oplossingsgerichte therapie: een vorm van gedragstherapie [The Power of Solution-Focused Therapy: A Form of Behavior Therapy]. Gedragstherapie [Behavior Therapy], 38(1), 5-16.

Bannink, F. P. (2006a). Oplossingsgerichte Mediation [SolutionFocused Mediation]. Amsterdam: Harcourt (Reed Elsevier).

Bannink, F. P. (2006b). Oplossingsgerichte mediaton [SolutionFocused Mediation]. Tijdschrift Conflicthantering [Journal of Conflict Management], 7, 143-145.

Bannink, F. P. (2006c). Oplossingsgerichte Vragen. Handboek oplossingsgerichte gespreksvoering [Solution-Focused Questions. Handbook solution-focused interviewing]. Amsterdam: Harcourt (Reed Elsevier).

Bannink, F. P. (2006d). De geboorte van oplossingsgerichte cognitieve gedragstherapie [The birth of solution-focused cognitive behavior therapy]. Gedragstherapie [Behavior Therapy], 39(3), 171-183.

Beck, J. S. (1995). Cognitive Therapy: Basics and beyond. New York: Guildford.

Berg, I. K., \& Miller, S. D. (1992). Working with the problem drinker: A solution focused approach. New York: Norton.

Berg, I. K., \& Steiner, T. (2003). Children's solution work. New York: Norton.

Cantwell, P., \& Holmes, S. (1994). Social construction: A paradigm shift for systemic therapy and training. The Australian and New Zealand Journal of Family Therapy, 15, 17-26.

Cauffman, L. (2003). Oplossingsgericht management \& coaching [Solution-Focused Management \& Coaching]. Utrecht: Lemma.

Cepeda, L. M., \& Davenport, D. S. (2006). Person-centered therapy and solution-focused brief therapy: An integration of present and future awareness. Psychotherapy: Theory, Research, Practice, Training, 43(1), 1-12.

de Jong, P., \& Berg, I. K. (1997). Interviewing for solutions. Pacific Grove California: Brooks/Cole.

de Shazer, S. (1984). The death of resistance. Family Process, 23, 7993.

de Shazer, S. (1985). Keys to solution in brief therapy. New York: Norton.

de Shazer, S. (1991). Putting difference to work. New York: Norton.

de Shazer, S. (1994). Words were originally magic. New York: Norton.

Dolan, Y. (1991). Resolving sexual abuse. New York: Norton.

Duncan, B. L., Miller, S. D., \& Sparks, A. (2004). The heroic client: A revolutionary way to improve effectiveness through client-directed, outcome-informed therapy. New York: Jossey-Bass.

Duncan, B. (2005). What's right with you? Debunking dysfunction and changing your life. Deerfield Beach, FL: Health Communications.

Gingerich, W. J., \& Eisengart, S. (2000). Solution-Focused Brief Therapy: A review of the outcome research. Family Process, 39, 477498.

Goei, S. L., \& Bannink, F. P. (2005). Oplossingsgericht werken in remedial teaching [Solution-Focused Remedial Teaching]. Remediaal, tijdschrift voor leer-en gedragsproblemen in het volbve [Remediaal, Journal of behavior problems in schools], 5(3), 1926.

Kazdin, A. E. (2006). Arbitrary metrics: Implications for identifying evidence-based treatments. American Psychologist, 61, 42-49.

Lang, P. J. (1985). The cognitive psychophysiology of emotion: fear and anxiety. In A. H. Tuma \& J. Maser (Eds.), Anxiety and the anxiety disorders. New Jersey: Erlbaum.

Metcalf, L. (1998). Solution focused group therapy. New York: Free Press.

Miller, S. D., Hubble, M. A., \& Duncan, B. L. (Eds.) (1996). The handbook of solution-focused brief therapy. San Francisco: JosseyBass. 
O’Hanlon, B., \& Bertolino, B. (1998). Even from a broken web. New York: Wiley.

O'Hanlon, B., \& Rowan, T. (1999). Solution oriented therapy for chronic and severe mental illness. New York: Norton.

Rossi, E. L. (Ed.) (1980). The nature of hypnosis and suggestion by Milton Erickson (collected papers). New York: Irvington.

Selekman, M. D. (1993). Pathways to change. New York: Guilford.

Selekman, M. D. (1997). Solution-focused therapy with children. New York: Guilford.

Seligman, M. E. P. (2002). Authentic happiness. New York: Free Press. Siegel, D. J. (1999). The developing mind. New York: Guilford.

Stams, G. J., Dekovic, M., Buist, K., \& de Vries, L. (2006). Effectiviteit van oplossingsgerichte korte therapie; een meta-analyse [Efficacy of solution-focused brief therapy: a meta-analysis]. Gedragstherapie \{Behavior Therapy], 39(2), 81-94.
Walter, J. L., \& Peller, J. E. (1992). Becoming solution-focused in brief therapy. New York: Brunner/Mazel.

Walter, J. L., \& Peller, J. E. (2000). Recreating brief therapy. New York: Norton.

Watzlawick, P., Weakland, J. H., \& Fisch, R. (1974). Change: Principles of problem formation and problem resolution. New York: Norton.

Westra, J., \& Bannink, F. P. (2006). 'Simpele' oplossingen! Oplossingsgericht werken bij mensen met een lichte verstandelijke beperking. ['Simple' solutions! A Solution-Focused Approach in Working with Mentally Handicapped Clients]. PsychoPraxis, 8(4), 158162.

Westra, J., \& Bannink, F. P. (2006). 'Simple' solutions! Oplossingsgericht werken bij mensen met een lichte verstandelijke beperking. ['Simple' solutions! A Solution-Focused Approach in Working with Mentally Handicapped Clients]. PsychoPraxis, 8(5), 213218 . 